\title{
Gardenia jasminoides Ellis Fruit Extracts Attenuated Colitis in 2,4,6-Trinitrobenzenesulfonic Acid-Induced Rats
}

\author{
Jing Liu $\left(\mathbb{D},{ }^{1}\right.$ Chao Yang $\left(\mathbb{D},{ }^{1}\right.$ Zhigui Wu $\left(\mathbb{D},{ }^{1,2}\right.$ Jianguo Pei $\mathbb{D}^{1},{ }^{1}$ Yao Chen $\left(\mathbb{D},{ }^{1}\right.$ Xiao Huang $(\mathbb{D}){ }^{1}$ \\ Sha Gao $\mathbb{D}^{1},{ }^{1}$ Rui Kan $\mathbb{D},{ }^{1}$ Wenna Zhang $\mathbb{D},{ }^{3}$ Saisai Xie $\mathbb{D}^{4},{ }^{4}$ and Xiaomei Fu $\mathbb{D}^{1,2}$ \\ ${ }^{1}$ School of Pharmacy, Jiangxi University of Chinese Medicine, Nanchang 330006, China \\ ${ }^{2}$ FAN Cuisheng Studio of National Famous TCM, Nanchang 330006, China \\ ${ }^{3}$ School of Life Sciences, Anhui University, Hefei 230601, Anhui, China \\ ${ }^{4}$ National Pharmaceutical Engineering Center for Solid Preparation in Chinese Herbal Medicine, \\ Jiangxi University of Chinese Medicine, Nanchang 330006, China \\ Correspondence should be addressed to Saisai Xie; xiesaisainanchang@hotmail.com and Xiaomei Fu; smilefxm@163.com
}

Received 4 March 2021; Revised 5 August 2021; Accepted 28 October 2021; Published 15 December 2021

Academic Editor: Yibin Feng

Copyright (C) 2021 Jing Liu et al. This is an open access article distributed under the Creative Commons Attribution License, which permits unrestricted use, distribution, and reproduction in any medium, provided the original work is properly cited.

\begin{abstract}
Ulcerative colitis (UC) is a relapsing inflammatory disease with an unknown precise etiology. The purpose of this study is to investigate the protective effects of Gardenia jasminoides Ellis fruit extracts (GFE) on 2,4,6-trinitrobenzenesulfonic acid (TNBS)-induced colitis in rats. GFE $(50 \mathrm{mg} / \mathrm{kg}, 100 \mathrm{mg} / \mathrm{kg})$ were administered orally for 7 days after induction. Meanwhile, the chemical components of GFE were performed by UPLC-QTOF-MS/MS. GFE significantly decreased DAI scores and ameliorated macroscopic and histologic damage. It also reduced the levels of MPO, NO, MDA, IL- $1 \beta$, TNF- $\alpha$, and IL-6, while increasing the level of SOD. Moreover, 56 components were identified in GFE using a UPLC-QTOF-MS/MS method, which can be categorized into six structural groups. Our results indicated that GFE has an ameliorative effect on TNBS-induced colitis in rats, which may further verify its anti-inflammatory and antioxidative properties. Therefore, GFE can be a promising protective agent of colitis that deserves further investigation.
\end{abstract}

\section{Introduction}

Ulcerative colitis (UC) is a relapsing inflammatory disease that affects the mucosal layer of the rectum and colon. The symptoms of UC include chronic diarrhea, stomach pain, blood in stool, and weight loss in the clinic $[1,2]$. It was found that UC occurs more and more commonly and worldwide in recent years, and the long-term abdominal discomfort already lowers the life quality of patients. Meanwhile, UC is widely accepted as a risk factor for colorectal cancer according to the clinical data [3]. Hence, World Health Organization lists UC as a miscellaneous problem.

Despite the precise cause of UC has not yet been completely elucidated, it is wildly considered that proinflammatory cytokines such as interleukin- $1 \beta(1 \mathrm{~L}-1 \beta)$, tumor necrosis factor- $\alpha$ (TNF- $\alpha$ ), and interleukin-6 (1L-6) play an essential role in the process of the pathogenesis and progression of UC $[4,5]$. Current treatments of UC mainly rely on anti-inflammatory medicines such as aminosalicylates and immunosuppressive and corticosteroid agents. However, most of these drugs have lots of unacceptable adverse effects, such as poor tolerance and high recurrence rate, which are not quite suitable for long-term treatment [6]. Therefore, it is still urgent to search new safe and effective agents for adjunct therapies.

Recently, more and more studies have focused on natural products as alternative or complimentary medicines for UC treatment. A series of natural products had been confirmed to be able to treat UC through anti-inflammatory actions, such as Forsythia suspensa Fructus, Eucommia ulmoides leaf, and brusatol, which can potentially enlarge the scope of drug candidates for UC treatment as well [7-9].

Gardenia jasminoides Ellis is a flowering plant belonging to Rubiaceae family. Its fruit has been used as food coloring in oriental countries [10]. As a natural plant, the fruit is used 
not only as a food but also as a medicine to treat hepatic disorders, headache, jaundice, inflammation, and hypertension [11-13]. Moreover, many bioactive ingredients from Gardenia jasminoides Ellis fruit extracts (GFE) such as iridoids, crocins, and organic acids have also shown anti-inflammatory effects. Specifically, geniposide and chlorogenic acid have shown good protective effects in rat colitis models $[14,15]$. Taken together, GFE has potential for the treatment of UC.

Therefore, the present study is to investigate whether GFE could have a protective effect in the rat colitis model induced by trinitrobenzene sulphonic acid (TNBS) and its mechanisms associated and to identify its bioactive ingredients by UPLC-QTOF-MS/MS.

\section{Materials and Methods}

2.1. Chemicals, Reagents, and Plant Material. The fruits of Gardenia jasminoides Ellis were collected from the GAP Base District of Jiangxi Province, China, and identified by Professor Cuisheng Fan, College of Pharmacy of Jiangxi University of Traditional Chinese Medicine. A voucher specimen (GJ-181027) was deposited at the department of identificology of Chinese Materia Medica of Jiangxi University of Traditional Chinese Medicine. TNBS was obtained from Sigma-Aldrich, USA. Sulfasalazine (SASP) was obtained from Shanghai Xinyi Tianping Pharmaceutical, China. Myeloperoxidase (MPO) determination kit was obtained from Jiancheng Bioengineering Institute, China; nitric oxide (NO), malondialdehyde (MDA), and superoxide dismutase (SOD) assay kits were obtained from Beyotime Institute of Biotechnology, China. The interleukin-1 $\beta$ (IL$1 \beta$ ), necrosis factor- $\alpha$ (TNF- $\alpha$ ), and interleukin-6 (IL-6) ELISA kits were obtained from MultiSciences (Lianke) Biotech, China. Acetonitrile, methanol, and formic acid were all of HPLC grade and were purchased from Merck, Germany. Ultrapure water was prepared by a Milli-Q system (Millipore, Bedford, USA).

2.2. Preparation of GFE. The fruits $\left(1500^{\circ} \mathrm{g}\right)$ were crushed, extracted with $70 \%$ aqueous ethanol for 2 hours under reflux, and extracted twice. The extract was concentrated by rotary evaporator and dried with lyophilizer. The yield of the extract was $21.39 \%(\mathrm{w} / \mathrm{w})$. The dried extract was kept at $-20^{\circ} \mathrm{C}$.

2.3. UPLC-QTOF-MS/MS Analysis. The chemical compositions of GFE were analysed by UPLC-QTOF-MS/MS. The dried extract $(1 \mathrm{mg})$ was dissolved in $1 \mathrm{~mL}$ acetonitrile and then filtered through a $0.22 \mu \mathrm{m}$ membrane filter. UPLC analysis was performed with a Shimadzu Prominence UPLC system (Nexera UHPLC LC-30A, Kyoto, Japan) comprised of a LC-30A binary pump, a LC-30AD solvent delivery system, a SIL-30AC autosampler, and a CTO-30AC column oven. Separation was carried on an ACE Excel Super C18 analytical column $(2.1 \times 50 \mathrm{~mm}, 1.7 \mu \mathrm{m})$ at $40{ }^{\circ} \mathrm{C}$. The mobile phase consisted of $(A)$ water- $0.1 \%$ formic acid and (B) acetonitrile: $0-10 \mathrm{~min}, 5-15 \% \mathrm{~B} ; 10-12 \mathrm{~min}, 15-21 \% \mathrm{~B}$;
$12-15 \mathrm{~min}, 21 \% \mathrm{~B} ; 15-18 \mathrm{~min}, 21-23 \% \mathrm{~B} ; 18-20 \mathrm{~min}$, 23-50\% B; 20-30 min, 50-95\% B; 30-32 min, 95\% B. $3 \mu \mathrm{l}$ sample solution was injected and the flow rate was $0.3 \mathrm{~mL} /$ $\min$.

The mass data were recorded on a triple TOF $5600^{+}$mass spectrometer (AB Sciex, USA), equipped with UPLC system. Samples were analysed in negative ion mode and the mass scan range was set from $\mathrm{m} / z 200$ to $\mathrm{m} / z 1000$. The other operation parameters in negative mode were optimized as follows: ion spray voltage, $-4500 \mathrm{~V}$; ion source temperature, $500^{\circ} \mathrm{C}$; nebulizer gas (GS1), $50 \mathrm{psi}$; curtain gas pressure, $40 \mathrm{psi}$; heater gas (GS2), $50 \mathrm{psi}$; declustering potential, $-100 \mathrm{~V}$; collision energy, $-45 \mathrm{eV}$; and collision energy spread, $( \pm) 15 \mathrm{eV}$. All data acquisition and analysis were used by the PeakView 1.2 software (AB Sciex, USA).

2.4. Animals and Treatment. Healthy male Sprague-Dawley (SD) rats (180-220 g) were purchased from Hunan SJA Laboratory Animal Co., Ltd. (Hunan, China; Certificate of Conformity: SCXK2013-0004). Animals were housed in polypropylene cages at $22 \pm 2{ }^{\circ} \mathrm{C}$, under $12 \mathrm{~h}$ day/night cycles. Rats were allowed free access to food and water. All procedures and experimental protocols were approved by Institutional Animals Ethics Committee of Jiangxi University of Traditional Chinese Medicine (certificate number: 201901112) and were carried out according to international standards and ethical guidelines on animal welfare.

Rat model of colitis was produced following the method described previously [16]. A catheter was inserted into the rat colon and then TNBS-ethanol solution $(50 \%, \mathrm{v} / \mathrm{v})$ was slowly administered at a dose of $0.5 \mathrm{~mL} / \mathrm{kg}$ though the catheter. The control group of rats was treated with $50 \%$ ethanol solution. All rats were kept in a vertical position for $30 \mathrm{~s}$ to prevent from leaking out before returning to their cage. Rats were distributed into five groups of seven rats each: control group, TNBS group, SASP group (500 mg/kg), and GFE treated groups ( $50 \mathrm{mg} / \mathrm{kg}, 100 \mathrm{mg} / \mathrm{kg}$ ). The TNBS and control groups were administered orally with $0.9 \%$ saline at the same volume. All drugs were administered orally for 7 consecutive days after induction. Rats were sacrificed under anesthesia to collect specimens on the 8 th day.

2.5. Disease Activity Index Evaluation. The rats' body weight, stool occult, and stool formation were recorded daily to calculate disease activity index (DAI) after modeling (Day 2). DAI was determined according to the previously scoring system [17].

2.6. Macroscopic Scoring of Colitis. After sacrificing the rats, the colons were removed and then flushed with ice-cold normal saline for macroscopic observation. The macroscopic scores were determined according to the criteria described in previous studies with a total score of 4 [18] (Table.1). 
TABLE 1: Histopathological scoring pattern in colon tissue.

\begin{tabular}{lc}
\hline Histopathological scoring & Microscopic colon damage \\
\hline 0 & Normal colonic tissue \\
1 & Inflammation or focal ulceration limited to the mucosa \\
2 & Focal or extensive ulceration and inflammation limited to the mucosa and the submucosa \\
3 & Focal or extensive ulceration and inflammation limited with involvement of the muscularis propria \\
4 & Focal or extensive ulceration and inflammation limited with involvement of the serosa \\
5 & Extensive ulceration and transmural inflammation with involvement of the serosa
\end{tabular}

2.7. Histological Assessment of Colitis. After the macroscopic assessment, about $0.5 \times 0.5 \mathrm{~cm}^{2}$ sections of colon tissues were fixed in $4 \%$ formalin, embedded in paraffin, and then stained with hematoxylin and eosin (H\&E). The histopathological scores were assessed by the previous standard with a total score of 5 [19]. The other sections from the clean colon lesion were kept at $-80^{\circ} \mathrm{C}$ for further analysis.

2.8. Measurement of MPO, SOD, MDA, NO, and Proinflammatory Cytokine in Colonic Tissues. The activities of MPO, SOD, MDA, and NO were detected with the corresponding test kits for the supernatants of the colonic tissues. The levels of TNF- $\alpha$, IL- $1 \beta$, and IL- 6 of the colonic tissues were measured using ELISA assay kits.

2.9. Statistical Analysis. Results were presented as mean \pm SD (standard deviation) using SPSS 20.0 software. Statistical differences were carried out by one-way ANOVA followed by Dunnett's test. $P$ values $<0.05$ were considered statistically significant.

\section{Results}

3.1. UPLC-ESI-Q-TOF-MS/MS Profiles of GFE. The components of GFE were analysed by UPLC-ESI-Q-TOF/MS. A total of 56 components were identified based on literatures and the detailed mass spectrometry data, while Table 2 shows the retention times, proposed formula, MS and fragments, and the identification results for the peaks labeled in the total ion flow chromatogram of GFE (Figure 1) [20, 21]. The components were mainly categorized into six structural groups, including iridoids, triterpenes, flavonoids, carotenoids, organic acids, and monoterpenoids.

3.2. Effects of GFE on DAI. DAI score is a notable index to assess the severity of colitis. As shown in Figure 2, compared with the control group, the DAI score was significantly increased in TNBS group $(p<0.01)$ from Day 1 , and treatment with GFE $(50 \mathrm{mg} / \mathrm{kg}, 100 \mathrm{mg} / \mathrm{kg})$ caused a significant decrease in the DAI score compared to the TNBS group at Day 3 and Day 4, respectively.

3.3. Macroscopic Changes. Macroscopic changes are major indicators to evaluate the severity of colitis observed in rats administered with TNBS. In this study, macroscopic inspection of the colons displayed the presence of severe ulceration, edema, and tissue necrosis in TNBS group. In contrast, SASP and GFE $(50 \mathrm{mg} / \mathrm{kg}, 100 \mathrm{mg} / \mathrm{kg})$ treatment caused a remarkable loss in the macroscopic lesion in colonic tissue (Figure 3(a)). The corresponding macroscopic scores were also presented in Figure 3(b). The macroscopic score of TNBS group was dramatically increased compared with the control group $(3.50 \pm 0.55$ vs. $0.29 \pm 0.49, p<0.01)$. This indicated that the model was successfully established. Treatment with SASP or GFE $(50 \mathrm{mg} / \mathrm{kg}, 100 \mathrm{mg} / \mathrm{kg})$ significantly decreased macroscopic sores compared with TNBS group.

3.4. Histological Changes. The histological study of colonic tissue showed inflammatory cell infiltration in the mucosa, loss of goblet cells, and epithelium and deformed or disappeared crypt in the TNBS group. The histologic sections of GFE $(50 \mathrm{mg} / \mathrm{kg}, 100 \mathrm{mg} / \mathrm{kg}$ ) or SASP groups showed moderate goblet cell loss, improvement of the crypt architecture, and mild inflammatory cell infiltration compared to those of the TNBS group (Figure 4(a)). The histological scores of GFE $(50 \mathrm{mg} / \mathrm{kg}, 100 \mathrm{mg} / \mathrm{kg}$ ) or SASP were also significantly decreased compared to the TNBS group (Figure 4(b)).

3.5. Effects of GFE on the MPO, SOD, MDA, and NO Levels. Treatment of rats with TNBS caused a significant increase in the colonic MPO levels $(1.07 \pm 0.12 \mathrm{U} / \mathrm{g}$ vs. $0.32 \pm 0.057 \mathrm{U} / \mathrm{g}$, $p<0.01)$ compared with that observed in the control group, and the colonic MPO levels were remarkably decreased $(p<0.01)$ by the treatment of $500 \mathrm{mg} / \mathrm{kg}$ SASP $(0.55 \pm 0.085 \mathrm{U} / \mathrm{g}), 50 \mathrm{mg} / \mathrm{kg}(0.59 \pm 0.073 \mathrm{U} / \mathrm{g})$, and $100 \mathrm{mg} /$ $\mathrm{kg}$ GFE $(0.54 \pm 0.078 \mathrm{U} / \mathrm{g})$, respectively (Figure 5(a)).

The SOD levels in the TNBS group were dramatically decreased in comparison to the control group $(27.12 \pm 4.86 \mathrm{U} / \mathrm{mg}$ vs. $64.59 \pm 7.59 \mathrm{U} / \mathrm{mg}, p<0.01)$. Treatment with SASP and GFE $(50 \mathrm{mg} / \mathrm{kg}, 100 \mathrm{mg} / \mathrm{kg})$ increased significantly the level of SOD in the colon $(45.17 \pm 8.36 \mathrm{U} /$ $\mathrm{mg}, 35.81 \pm 4.25 \mathrm{U} / \mathrm{mg}$, and $43.98 \pm 4.37 \mathrm{U} / \mathrm{mg}, p<0.05$, $p<0.01$; Figure $5(\mathrm{~b}))$. Compared to the control group, higher level of colonic MDA was found in TNBS group $(15.83 \pm 2.26 \mathrm{nmol} / \mathrm{mg}$ vs. $45.95 \pm 7.04 \mathrm{nmol} / \mathrm{mg}, p<0.01)$. The MDA level was decreased to $25.08 \pm 4.93 \mathrm{nmol} / \mathrm{mg}$, $33.70 \pm 6.43 \mathrm{nmol} / \mathrm{mg}$, and $25.86 \pm 5.04 \mathrm{nmol} / \mathrm{mg}$ after treatment with SASP and GFE $(50 \mathrm{mg} / \mathrm{kg}, 100 \mathrm{mg} / \mathrm{kg})$ (Figure 5(c)). The higher colonic level of NO was in the TNBS group in comparison with the control group $(16.48 \pm 2.64 \mu \mathrm{mol} / \mathrm{g} v s .5 .55 \pm 1.78 \mu \mathrm{mol} / \mathrm{g}, \quad p<0.01)$. The colonic NO level was significantly decreased by treatment with SASP and different doses of GFE $(9.02 \pm 1.82 \mu \mathrm{mol} / \mathrm{g}$, 
TABLE 2: Structure of the 56 compounds detected in GFE.

\begin{tabular}{|c|c|c|c|c|c|c|c|}
\hline No. & $\begin{array}{c}t \\
(\min )\end{array}$ & $\begin{array}{c}\text { Mass }(\mathrm{m} / \\
z)\end{array}$ & $\begin{array}{l}\text { Calculated } \\
\text { ass }(\mathrm{m} / z)\end{array}$ & $\begin{array}{l}\text { Proposed } \\
\text { formula }\end{array}$ & Fragments & Deduced structure & Type \\
\hline 1 & 1.77 & 389.1077 & 389.1084 & $\mathrm{C} 16 \mathrm{H} 22 \mathrm{O} 11$ & $227,183,165,139$ & Deacetyl asperulosidic acid & Iridoids \\
\hline 2 & 2.13 & 373.1130 & 373.1135 & $\mathrm{C} 16 \mathrm{H} 22 \mathrm{O} 10$ & $193,149,123,167,121,101,211$ & Gardoside & Iridoids \\
\hline 3 & 2.58 & 391.1237 & 391.1240 & $\mathrm{C} 16 \mathrm{H} 24 \mathrm{O} 11$ & $229,211,193,185,167,149$ & Shanzhiside & Iridoids \\
\hline 4 & 2.64 & 373.1127 & 373.1135 & $\mathrm{C} 16 \mathrm{H} 22 \mathrm{O} 10$ & $149,123,105,211$ & Geniposidic acid & Iridoids \\
\hline 5 & 3.28 & 449.1286 & 449.1295 & $\mathrm{C} 17 \mathrm{H} 24 \mathrm{O} 11$ & $241,127,223,193,101$ & Scandoside methyl ester & iridoids \\
\hline 6 & 3.53 & 449.1288 & 449.1295 & $\mathrm{C} 17 \mathrm{H} 24 \mathrm{O} 11$ & $241,127,223,193,101$ & Gardenoside & Iridoids \\
\hline 7 & 3.86 & 345.1552 & 345.1549 & $\mathrm{C} 16 \mathrm{H} 26 \mathrm{O} 8$ & $165,121,183,101,89$ & Jasminoside B & Monoterpenoids \\
\hline 8 & 6.17 & 353.0872 & 353.0873 & C16H18O9 & 191,135 & Chlorogenic acid & Organic acids \\
\hline 9 & 6.64 & 549.1800 & 549.1820 & $\mathrm{C}_{23} \mathrm{H}_{34} \mathrm{O}_{15}$ & $225,123,101,207$ & Genipin-1- $\beta$-D-gentiobioside & Iridoids \\
\hline 10 & 8.02 & 387.1282 & 387.1291 & $\mathrm{C} 17 \mathrm{H} 24 \mathrm{O} 10$ & $225,123,101,207$ & Geniposide & Iridoids \\
\hline 11 & 9.28 & 375.1653 & 375.1655 & C17H27O9 & $113,89,101,59,85,71,143$ & Jasminoside $\mathrm{A} / E$ & Monoterpenoids \\
\hline 12 & 9.55 & 375.1650 & 375.1 & C17H27O9 & $113,89,101,59,85,71,143$ & Jasminoside $\mathrm{A} / E$ & Monoterpenoids \\
\hline 13 & 9.95 & 183.1039 & 183.1021 & $\mathrm{C} 10 \mathrm{H} 16 \mathrm{O} 3$ & $139,137,109,123$ & Jasminodiol & Monoterpenoids \\
\hline 14 & 10.46 & 351.1423 & 351.1420 & $\mathrm{C} 16 \mathrm{H} 24 \mathrm{O} 7$ & 167 & Zataroside B & Monoterpenoids \\
\hline 15 & 10.69 & 503.1747 & 503.1765 & $\mathrm{C} 22 \mathrm{H} 32 \mathrm{O} 13$ & $205,223,190$ & $\begin{array}{l}\text { 2-Methyl-L-erythritol-4-O-(6-O- } \\
\text { trans-sinapoyl)- } \beta \text {-D- } \\
\text { glucopyranoside }\end{array}$ & Organic acids \\
\hline 16 & 11.29 & 503.1747 & 503.1765 & $\mathrm{C} 22 \mathrm{H} 32 \mathrm{O} 13$ & $205,223,190$ & $\begin{array}{l}\text { 2-Methyl-L-erythritol-1-O-(6-O- } \\
\text { trans-sinapoyl)- } \beta \text {-D- } \\
\text { glucopyranoside }\end{array}$ & Organic acids \\
\hline 17 & 12.64 & 609.1437 & 609.1456 & $\mathrm{C} 27 \mathrm{H} 30 \mathrm{O} 16$ & $301,271,343$ & Quercetin-3-O-rutinoside & Flavonoids \\
\hline 18 & 12.76 & 429.2111 & 429.2122 & 6011 & $191,209,339,113,249$ & 10-O-Acetylgeniposide & Iridoids \\
\hline 19 & 12.79 & 609.1430 & 609.1456 & $\mathrm{C} 27 \mathrm{H} 30 \mathrm{O} 16$ & $301,300,151,179$ & Rutin & Flavonoids \\
\hline 20 & 13.13 & 463.0876 & 463.0863 & $\mathrm{C} 21 \mathrm{H} 20 \mathrm{O} 12$ & $300,301,271,151,255$ & Isoquercitrin & Flavonoids \\
\hline 21 & 13.30 & 581.2234 & 581.2234 & $38 \mathrm{O} 13$ & $401,389,371,356,265$ & $\begin{array}{l}\text { (+)-Lyoniresinol-3a-O-b- } \\
\text { glucopyranoside }\end{array}$ & Lignans \\
\hline 22 & 13.58 & 579.1695 & 579.1714 & $\mathrm{C} 27 \mathrm{H} 32 \mathrm{O} 14$ & $205,325,367,385,223,123$ & $6^{\prime}$-O-trans-Sinapoyl gardoside & Iridoids \\
\hline 23 & 13.81 & 539.1177 & 515.1190 & $\mathrm{C} 25 \mathrm{H} 24 \mathrm{O} 12$ & $353,173,179,191$ & $\begin{array}{c}\text { 3,4-Di-O-Caffeoylquinic acid/3,5- } \\
\text { Di-O-caffeoylquinic acid }\end{array}$ & Phenolic acids \\
\hline 24 & 13.91 & 565.1903 & 565.1921 & $\mathrm{C} 27 \mathrm{H} 34 \mathrm{O} 13$ & $325,265,223,295$ & $\begin{array}{l}\text { 11-(6-O-trans- } \\
\text { Sinapoylglucopyranosyl)- } \\
\text { gardendiol }\end{array}$ & Iridoids \\
\hline 25 & 14.25 & 539.1167 & 515.1190 & $\mathrm{C} 25 \mathrm{H} 24 \mathrm{O} 12$ & $353,173,179,191$ & $\begin{array}{c}\text { 3,4-Di-O-Caffeoylquinic acid/3,5- } \\
\text { Di-O-caffeoylquinic acid }\end{array}$ & Phenolic acids \\
\hline 26 & 14.29 & 491.2109 & 491.2129 & $\mathrm{C} 22 \mathrm{H} 36 \mathrm{O} 12$ & $167,323,221,125,263$ & Jasminoside $\mathrm{S} / \mathrm{H} / \mathrm{I}$ & Monoterpenoids \\
\hline 27 & 15.45 & 755.2377 & 755.2399 & C34H44O19 & $123,223,205,101,427$ & $\begin{array}{l}6^{\prime} \text {-O-trans-Sinapoyl genipin } \\
\text { gentiobioside }\end{array}$ & Iridoids \\
\hline 28 & 15.73 & 725.2278 & 725.2293 & $\mathrm{C} 33 \mathrm{H} 42 \mathrm{O} 18$ & $499,123,193,225$ & $\begin{array}{l}6^{\prime \prime} \text {-O-trans-Feruloyl-genipin } \\
\text { gentiobioside }\end{array}$ & Iridoids \\
\hline 29 & 16.30 & 659.15969 & 659.1612 & $\mathrm{C} 31 \mathrm{H} 32 \mathrm{O} 16$ & $497,335,353,191,161$ & $\begin{array}{l}\text { 3,4-Dicaffeoyl-5-(3-hydroxy-3- } \\
\text { methylglutaroyl) quinic acid }\end{array}$ & Phenolic acids \\
\hline 30 & 16.76 & 975.3686 & 975.3709 & $\mathrm{C} 44 \mathrm{H} 64 \mathrm{O} 24$ & $651,327,283,239$ & trans-Crocin $4 /$ cis-crocin 4 & Carotenoids \\
\hline 31 & 16.90 & 551.2115 & 551.2129 & $\mathrm{C} 27 \mathrm{H} 36 \mathrm{O} 12$ & $533,521,265,367$ & $\begin{array}{c}6^{\prime} \text {-O-trans-Sinapoyl jasminoside } \\
\text { L }\end{array}$ & Monoterpenoids \\
\hline 32 & 17.16 & 559.1433 & 559.1452 & $\mathrm{C} 27 \mathrm{H} 28 \mathrm{O} 13$ & $173,223,397$ & $\begin{array}{c}\text { 5-O-Caffeoyl-4-O-sinapoylquinic } \\
\text { acid }\end{array}$ & Phenolic acids \\
\hline 33 & 17.97 & 559.1432 & 559.1452 & 27H28O13 & $173,223,397$ & 4-Sinapoyl-5-caffeoylquinic acid & Phenolic acids \\
\hline 34 & 18.12 & 593.1845 & 870 & $28 \mathrm{H} 34 \mathrm{O} 14$ & $367,223,205,123$ & $6^{\prime}$ - trans-Sinapoyl geniposide & Iridoids \\
\hline 35 & 19.68 & 813.3158 & & C38H54O19 & $651,327,283$ & trans-Crocin $3 /$ cis-crocin 3 & Carotenoids \\
\hline 36 & 20.01 & 301.0351 & 301.0348 & $\mathrm{C} 15 \mathrm{H} 10 \mathrm{O} 7$ & $151,273,73$ & Quercetin & Flavonoids \\
\hline 37 & 20.19 & 679.2216 & 679.2238 & $\mathrm{C} 32 \mathrm{H} 40 \mathrm{O} 16$ & $531,225,123,147,101$ & $\begin{array}{l}\text { 6"-O-trans-p-Cinnamoyl genipin } \\
\text { gentiobioside }\end{array}$ & Iridoids \\
\hline 38 & 20.28 & 345.0611 & 345.0610 & C17H14O8 & $315,330,287$ & $\begin{array}{l}\text { 5,7,3,4-Tetrahydroxy-6,8- } \\
\text { dimethoxy flavone }\end{array}$ & Flavonoids \\
\hline 39 & 20.37 & 533.2006 & 533.2023 & $\mathrm{C} 27 \mathrm{H} 34 \mathrm{O} 11$ & $205,367,223,165,190$ & $\begin{array}{c}6^{\prime} \text {-O-trans-Sinapoyl jasminoside } \\
\text { A }\end{array}$ & Monoter \\
\hline 40 & 20.44 & 975.368 & 975.371 & C44H64O24 & $651,327,283,239$ & trans-Crocin $4 /$ cis-crocin 4 & Carotenoids \\
\hline 41 & 20.45 & 651.2630 & 651.2653 & $\mathrm{C} 32 \mathrm{H} 44 \mathrm{O} 14$ & $327,283,239$ & $\begin{array}{l}\text { cis-Crocin } 2 / \text { trans-crocin } 2 / \text { cis- } \\
\text { crocin } 2 / \text { trans-crocin } 2^{\prime}\end{array}$ & Carotenoids \\
\hline
\end{tabular}


TABle 2: Continued.

\begin{tabular}{|c|c|c|c|c|c|c|c|}
\hline No. & $\begin{array}{c}t \\
(\min )\end{array}$ & $\begin{array}{l}\text { Mass }(\mathrm{m} / \\
z)\end{array}$ & $\begin{array}{l}\text { Calculated } \\
\text { ass }(\mathrm{m} / z)\end{array}$ & $\begin{array}{l}\text { Proposed } \\
\text { formula }\end{array}$ & Fragments & Deduced structure & Type \\
\hline 42 & 20.54 & 533.20063 & 533.2023 & $\mathrm{C} 27 \mathrm{H} 34 \mathrm{O} 11$ & $205,367,223,165,190$ & 6'-O-trans-Sinapoyl jasminoside & Monoterpenoids \\
\hline 43 & 20.65 & 651.26332 & 651.2653 & $\mathrm{C} 32 \mathrm{H} 44 \mathrm{O} 14$ & $327,283,239$ & $\begin{array}{l}\text { cis-Crocin } 2 / \text { trans-crocin } 2 / \text { cis- } \\
\text { crocin } 2 / \text { trans-crocin } 2^{\prime}\end{array}$ & Carotenoids \\
\hline 44 & 20.70 & 813.3158 & 813.3181 & C38H54O19 & $651,327,283$ & trans-Crocin3/cis-crocin 3 & Carotenoids \\
\hline 45 & 20.80 & 375.0710 & 375.0716 & $\mathrm{C} 18 \mathrm{H} 16 \mathrm{O} 9$ & $360,345,330$ & $\begin{array}{l}\text { 4,5,6,7-Tetrahydroxy-3,3,5- } \\
\text { trimethoxyflavone }\end{array}$ & Flavonoids \\
\hline 46 & 20.89 & 329.0661 & 329.0661 & $\mathrm{C} 17 \mathrm{H} 13 \mathrm{O} 7$ & $314,299,271,227$ & $\begin{array}{l}\text { 2-(3,5-Dihyroxy-4- } \\
\text { ethoxyphenyl)-5-hydroxy-7- } \\
\text { methoxy- } 4 \text { H-chromen-4-one }\end{array}$ & Flavonoids \\
\hline 47 & 21.29 & 651.2632 & 651.2653 & $\mathrm{C} 32 \mathrm{H} 44 \mathrm{O} 14$ & $327,283,239$ & $\begin{array}{l}\text { cis-Crocin } 2 / \operatorname{trans} \text {-crocin } 2 / \text { cis- } \\
\text { crocin } 2 / \text { trans-crocin } 2^{\prime}\end{array}$ & Carotenoids \\
\hline 48 & 22.56 & 499.3035 & 499.3060 & $\mathrm{C} 30 \mathrm{H} 44 \mathrm{O} 6$ & $455,437,481,393$ & Dikamaliartanes A & Triterpenes \\
\hline 49 & 22.79 & 327.1596 & 327.1596 & $\mathrm{C} 20 \mathrm{H} 24 \mathrm{O} 4$ & 239,283 & Crocetin & Carotenoids \\
\hline 50 & 22.82 & 487.3405 & 487.3424 & $\mathrm{C} 30 \mathrm{H} 48 \mathrm{O} 5$ & $469,437,425,393$ & Erubigenin & Triterpenes \\
\hline 51 & 23.28 & 489.3558 & 489.3580 & $\mathrm{C} 30 \mathrm{H} 50 \mathrm{O} 5$ & 471,441 & Secaubrytriol & Triterpenes \\
\hline 52 & 23.61 & 269.0453 & 269.0450 & $\mathrm{C} 15 \mathrm{H} 10 \mathrm{O} 5$ & 241,225 & Genistein & Flavonoids \\
\hline 53 & 23.97 & 485.3249 & 485.3267 & $\mathrm{C} 30 \mathrm{H} 46 \mathrm{O} 5$ & $441,423,467,367$ & Gardenic acid B & Triterpenes \\
\hline 54 & 26.87 & 471.3458 & 471.3474 & $\mathrm{C} 30 \mathrm{H} 48 \mathrm{O} 4$ & $453,423,409$ & Quadrangularic acid E & Triterpenes \\
\hline 55 & 26.93 & 469.3302 & 469.3318 & $\mathrm{C} 30 \mathrm{H} 46 \mathrm{O} 4$ & $451,407,423$ & $\begin{array}{c}\text { 9,19-Cyclolanost-24-ene-3,23- } \\
\text { dione }\end{array}$ & Triterpenes \\
\hline 56 & 28.67 & 455.3515 & 455.3525 & $\mathrm{C} 30 \mathrm{H} 48 \mathrm{O} 3$ & $407,391,377$ & Ursolic acid/oleanolic acid & Triterpenes \\
\hline
\end{tabular}

$10.48 \pm 2.43 \mu \mathrm{mol} / \mathrm{g}, \quad$ and $\quad 8.88 \pm 1.84 \mu \mathrm{mol} / \mathrm{g}, \quad p<0.01$, Figure 5(d)).

3.6. Effects of GFE on the Proinflammatory Cytokines. The levels of TNF- $\alpha$, IL- $1 \beta$, and IL- $6 \beta$ were dramatically increased in the TNBS group compared with the control group $(8.48 \pm 1.30 \mathrm{ng} / \mathrm{g}$ vs. $2.82 \pm 0.54 \mathrm{ng} / \mathrm{g}, 0.99 \pm 0.17 \mathrm{ng} / \mathrm{g}$ vs. $0.33 \pm 0.078 \mathrm{ng} / \mathrm{g}, \quad 1.00 \pm 0.089 \mathrm{ng} / \mathrm{g}$ vs. $0.26 \pm 0.068 \mathrm{ng} / \mathrm{g}$, $p<0.01)$. Conversely, the colonic TNF- $\alpha$, IL- $1 \beta$, and IL- $6 \beta$ levels were notably decreased in both GFE $(50 \mathrm{mg} / \mathrm{kg}$, $100 \mathrm{mg} / \mathrm{kg}$ ) and SASP groups in comparison to the TNBS group $(p<0.05, p<0.01$; Figures $6(\mathrm{a})-6(\mathrm{c}))$.

\section{Discussion}

$\mathrm{UC}$ is a chronic inflammatory bowel disease which affects a million people around the world. Current treatment of UC is generally anti-inflammatory or immunosuppressive agents. However, most of these agents have many side effects and are proved to be inadequate for treatment. Thus, more and more natural products, especially medicinal plants, are considered as alternative treatments. GFE has been considered to have anti-inflammatory effect in previous studies. Therefore, we focused on the effect of GFE on TNBS-induced colitis in rats in the current study. TNBS-induced colitis model is one of the most appropriate models similar to human colitis in previous studies [1]. On this estimated model, DAI, macroscopic and histological changes were assessed in this study. GFE could reduce the DAI score and attenuate the macroscopic damage significantly induced by TNBS. The results of histological evaluation were consistent with macroscopic data, indicating that GFE treatment dramatically attenuated the destruction of the colonic tissue and its related inflammatory changes induced by TNBS. All these results above demonstrated that GFE had a noticeably protective effect against TNBS-induced colitis in rats. This efficacy was further proved by the investigation of biochemical and inflammatory biomarkers in colonic tissues.

It is known that reactive oxygen species (ROS) are involved in the initiation and progression of ulcerative colitis. Under normally physiological conditions, amounts of antioxidant systems control ROS. Nevertheless, excessive ROS released in inflammatory colitis lesions induce oxidative stress $[22,23]$. MDA is an important oxidative stress indicator which is produced by lipid peroxidation. It was documented that the tissue level of MDA was increased in TNBS-induced colitis, which can also be observed in our study [24]. Meanwhile, the intestinal cells possess more efficient antioxidant defense to reduce the harmful effects of oxidative stress. SOD is a crucial antioxidant enzyme which could reduce oxidative damage and scavenge free radicals. Several studies also showed that the colonic SOD level was decreased in the colitis model $[25,26]$. The change trends of colonic MDA and SOD levels in model rats were consistent with previous literatures, which indicated that the colitis model was established in our experiments successfully. GFE administrations $(50 \mathrm{mg} / \mathrm{kg}, 100 \mathrm{mg} / \mathrm{kg}$ ) significantly decreased the concentration of MDA and increased the activity of SOD. These findings indicated that amelioration of colon damage with GFE at least partly was related to the reduction of oxidative stress.

$\mathrm{NO}$ is a free gaseous signaling molecule that is synthesized by inducible nitric oxide synthase. Previous studies have shown that overproduction of NO leads to colonic mucosal damage and implicates in the pathogenesis of colitis [27, 28]. Hence, NO is an important indicator in inflammatory bowel disease. Meanwhile, the activity of MPO is also an important 


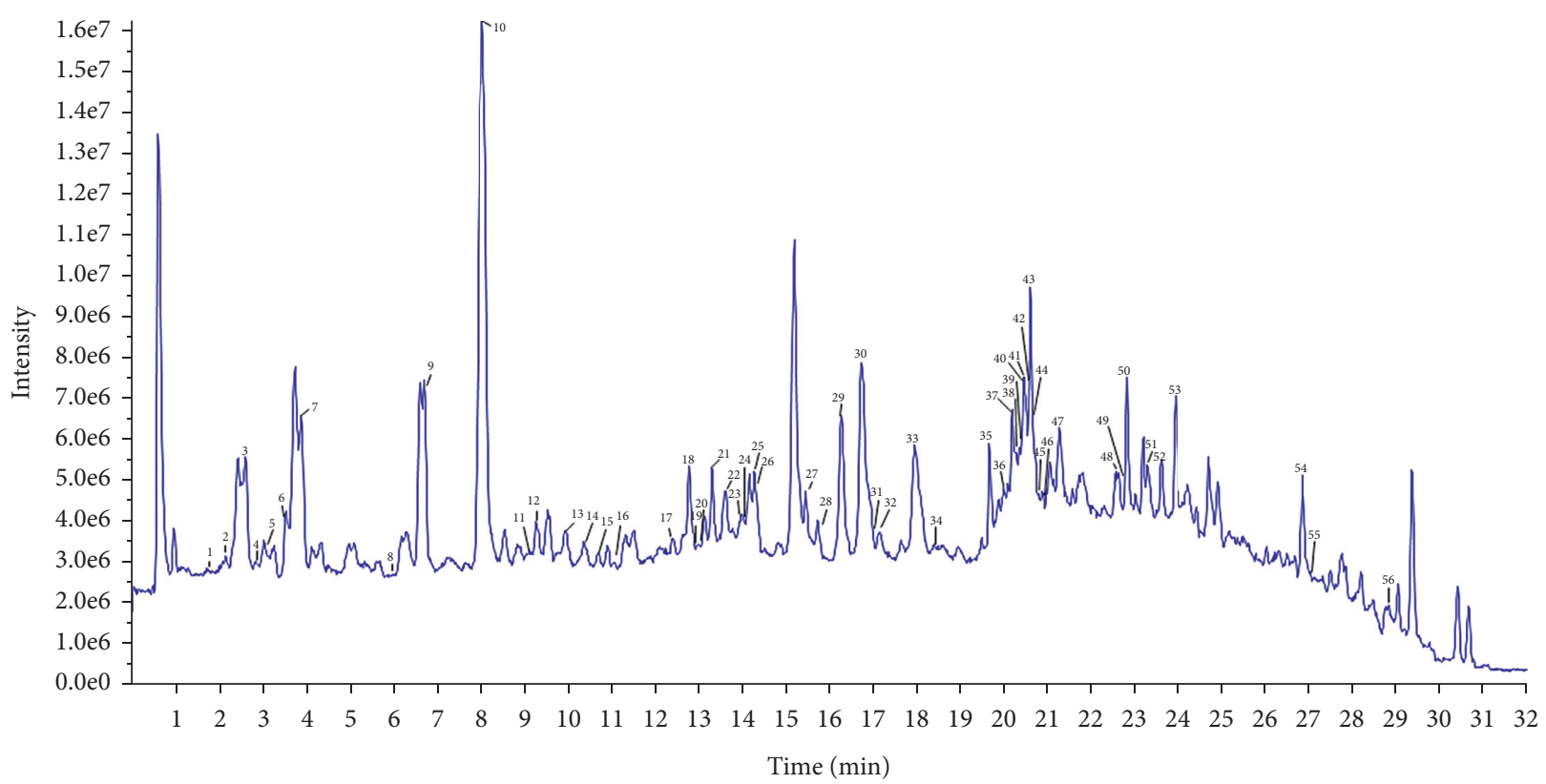

FIGURE 1: Total ion flow chromatogram of GFE in the negative ion mode by UPLC-Q-TOF/MS.

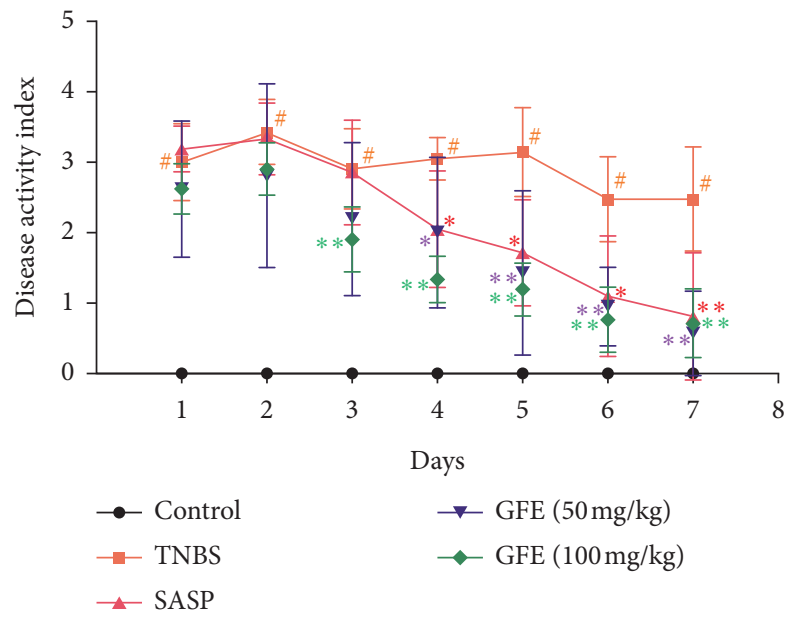

Figure 2: Effect of different doses of GFE ( $50 \mathrm{mg} / \mathrm{kg}, 100 \mathrm{mg} / \mathrm{kg})$ and SASP $(500 \mathrm{mg} / \mathrm{kg})$ on DAI scores of TNBS-induced colitis in rats. Data are showed as mean \pm SD. ${ }^{\#} p<0.01$ vs. control group; ${ }^{*} p<0.05$ and ${ }^{* *} p<0.01$ vs. TNBS group.

biomarker of neutrophils infiltration into the inflamed colonic tissue, which is commonly used to evaluate the severity degree of colonic inflammation in kinds of experimental studies and clinical trials $[29,30]$. In this study, the colonic MPO and NO levels were increased in TNBS group, revealing that consequent inflammation and recruitment occurred in rats induced by TNBS. Treatment with GFE showed remarkably decreased levels of MPO and NO in colonic tissue, thus indicating the effect of GFE treatment was associated with the anti-inflammatory property.

Proinflammatory cytokines such as TNF- $\alpha, 1 \mathrm{~L}-1 \beta$, and 1L-6 have essential roles in the pathological development of UC [31]. As previous studies demonstrated, the proinflammatory cytokine levels were increased in UC patients and TNBS-induced colitis rats model [32]. TNF- $\alpha$ could recruit leukocytes from the inflamed area and stimulate the expression of cytokines which is a key target molecule of taking part in intestinal inflammation $[33,34]$, and $1 \mathrm{~L}-1 \beta$ and $1 \mathrm{~L}-6$ are also important indicators in the progression of UC. IL- $1 \beta$ could stimulate the recruitment of neutrophils to the inflamed colonic tissue [35]. IL-6 plays an important role in enhancing T-cell survival and apoptosis resistance in the lamina propria at the inflamed site $[36,37]$. Therefore, targeting proinflammatory cytokines had become a therapeutic approach for UC patients. In the current study, treatment with GFE significantly decreased the colonic TNF$\alpha, 1 \mathrm{~L}-1 \beta$, and $1 \mathrm{~L}-6$ levels. These findings also indicated that GFE may influence the production of cytokines and inhibit immune inflammation.

Furthermore, this study explored the effective components in GFE by UPLC-ESI-Q-TOF/MS. 56 compounds of six main structural types in GFE, including iridoids, flavonoids, 

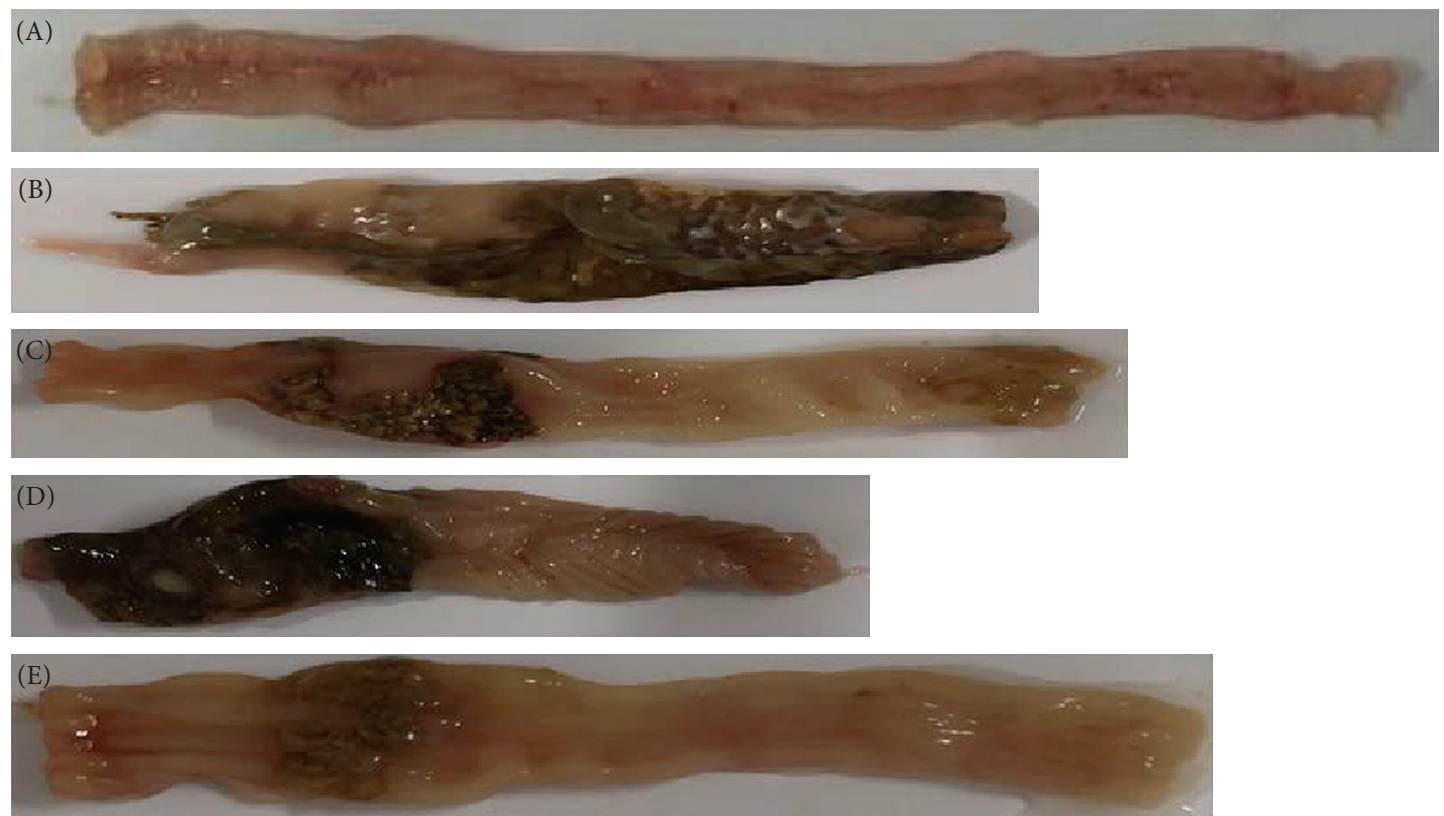

(a)

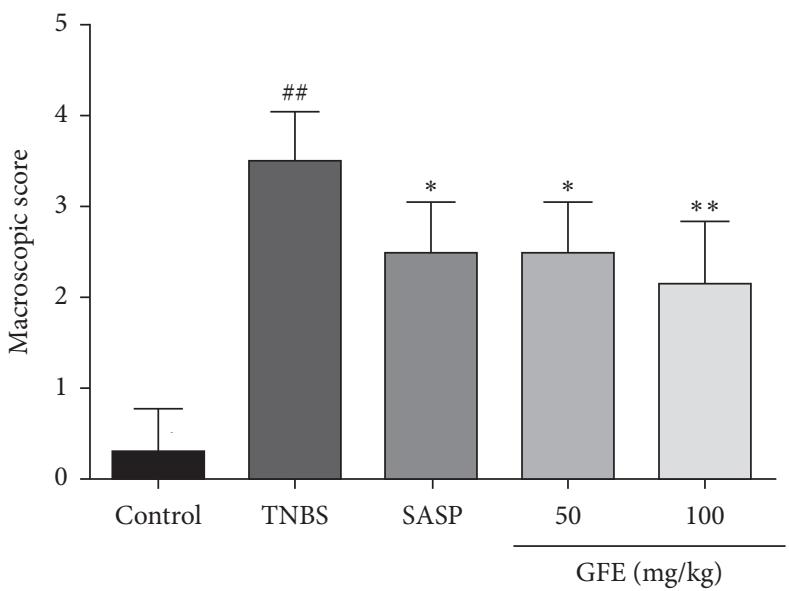

(b)

FIGURE 3: Effect of different doses of GFE $(50 \mathrm{mg} / \mathrm{kg}, 100 \mathrm{mg} / \mathrm{kg})$ and SASP $(500 \mathrm{mg} / \mathrm{kg})$ on colonic macroscopic appearance changes (A) and macroscopic score (B): (a) control group; (b) TNBS group; (c) SASP group; (d) GJEF treatment group, 50 mg/kg; (e) GJEF treatment group, $100 \mathrm{mg} / \mathrm{kg}$. Data are showed as mean $\pm \mathrm{SD}$. ${ }^{\# \#} p<0.001$ vs. control group; ${ }^{*} p<0.05$ and ${ }^{* *} p<0.01$ vs. TNBS group.

triterpenes, monoterpenoids, carotenoids, and phenolic acids were identified based on UPLC-ESI-QTOF/MS analysis. According to previous studies, iridoids-type compound (e.g., geniposide and genipin), carotenoids-type compound (e.g., crocin), and phenolic acid-type compound (e.g., chlorogenic acid and gallic acid) have been demonstrated to exhibit good antioxidant activity and anti-inflammatory activity [38-42]. Geniposide and chlorogenic acid had even been proved to treat UC in animal models through inflammatory pathways. Hence, the effect of the type of iridoids, carotenoids, and phenolic acid 


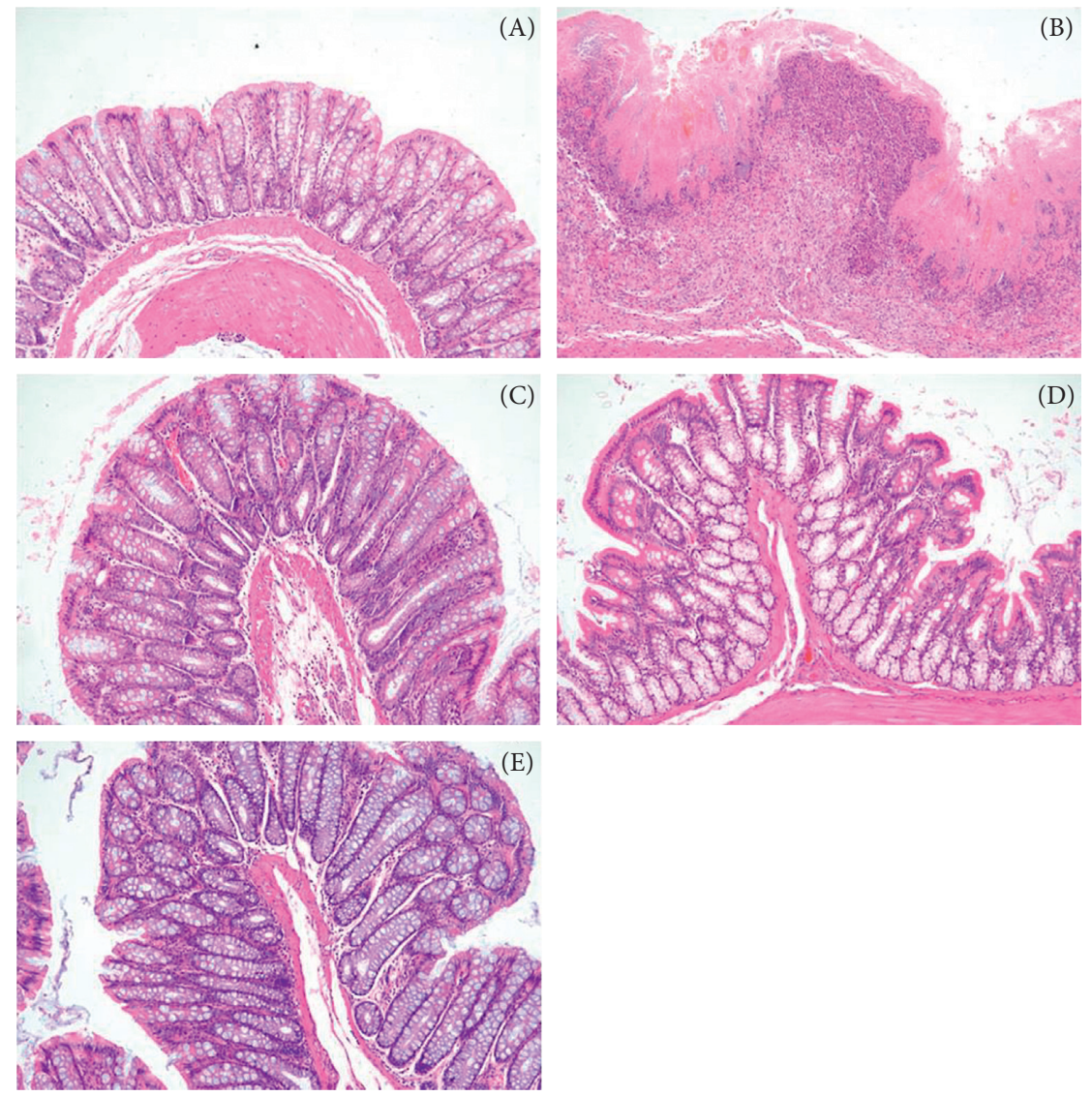

(a)

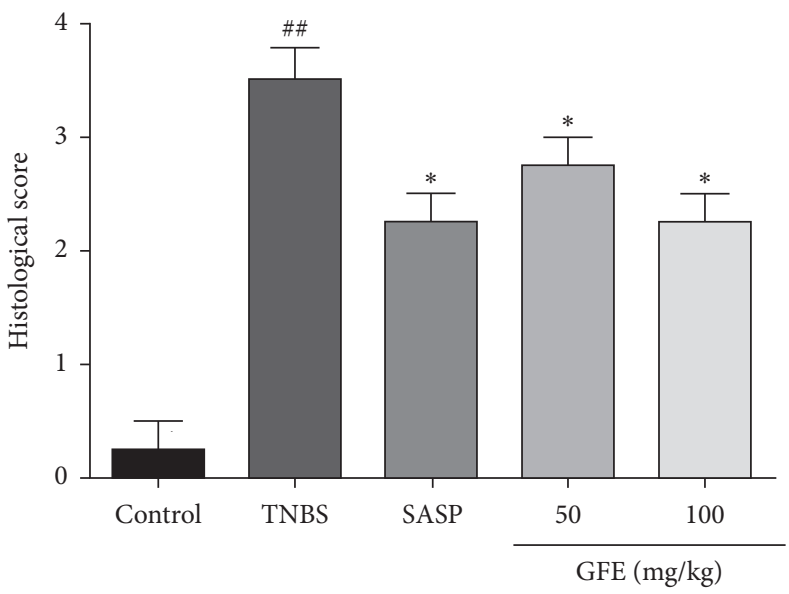

(b)

Figure 4: Effect of different doses of GFE (50 mg/kg, $100 \mathrm{mg} / \mathrm{kg})$ and SASP (500 mg/kg) on colonic histological changes (A) and histological scores (B): (a) control group; (b)TNBS group; (c) SASP group; (d) GFE treatment group, $50 \mathrm{mg} / \mathrm{kg}$; (e) GFE treatment group, $100 \mathrm{mg} / \mathrm{kg}$. Data are showed as mean \pm SD. ${ }^{\# \#} p<0.001 v$ s. control group; ${ }^{*} p<0.05$ and ${ }^{* *} p<0.01 v$ s. TNBS group. H\&E straining, magnification $100 \times$. 


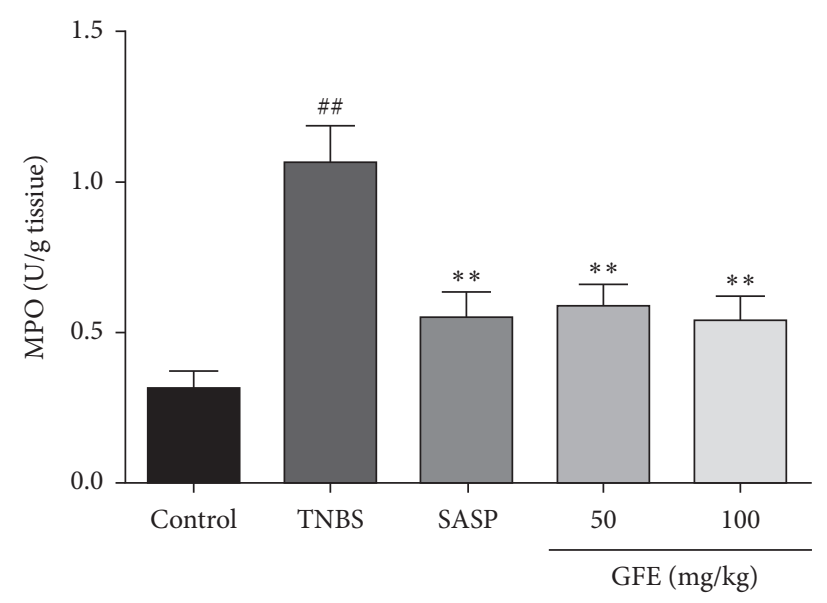

(a)

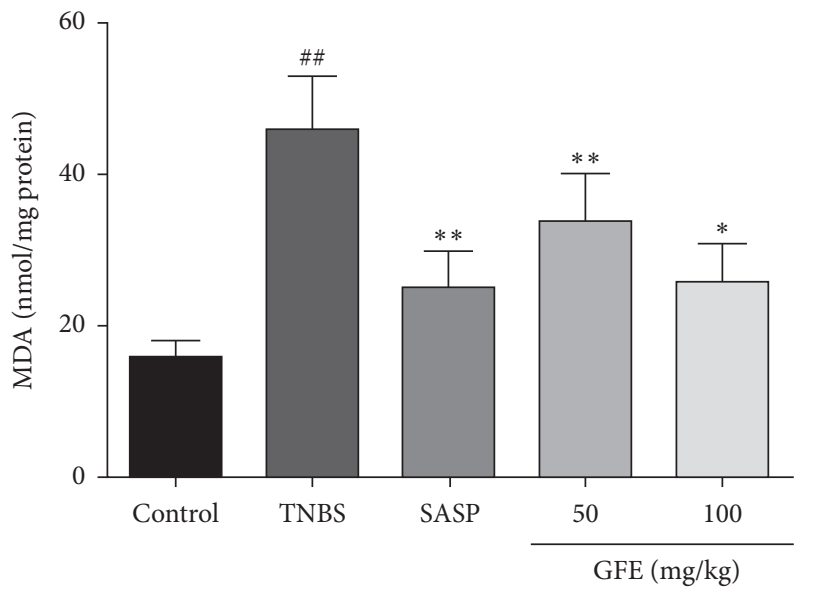

(c)

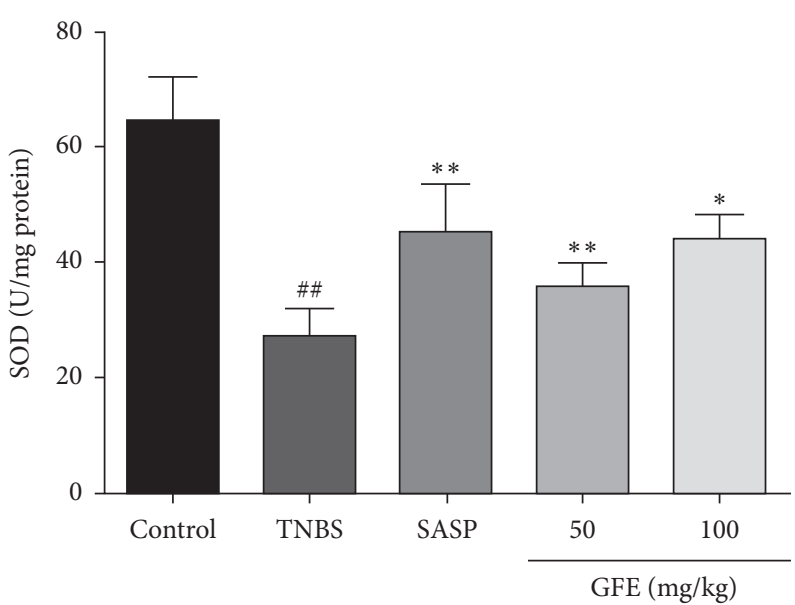

(b)

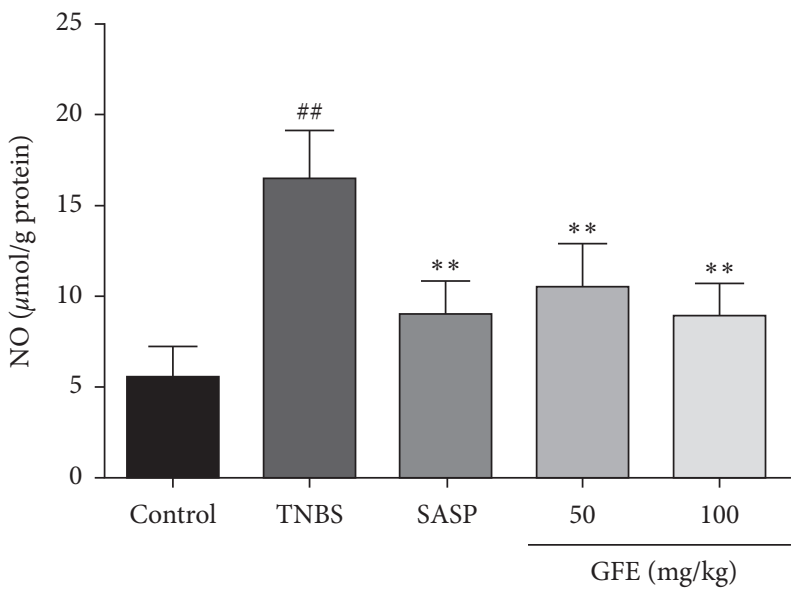

(d)

Figure 5: Effect of different doses of GFE (50 mg/kg, $100 \mathrm{mg} / \mathrm{kg}$ ) and SASP (500 mg/kg) on MPO (a), SOD (b), MDA (c), and NO (d). Data are showed as mean \pm SD. ${ }^{\# \#} p<0.001$ vs. control group; ${ }^{*} p<0.05$ and ${ }^{* *} p<0.01 v s$. TNBS group.

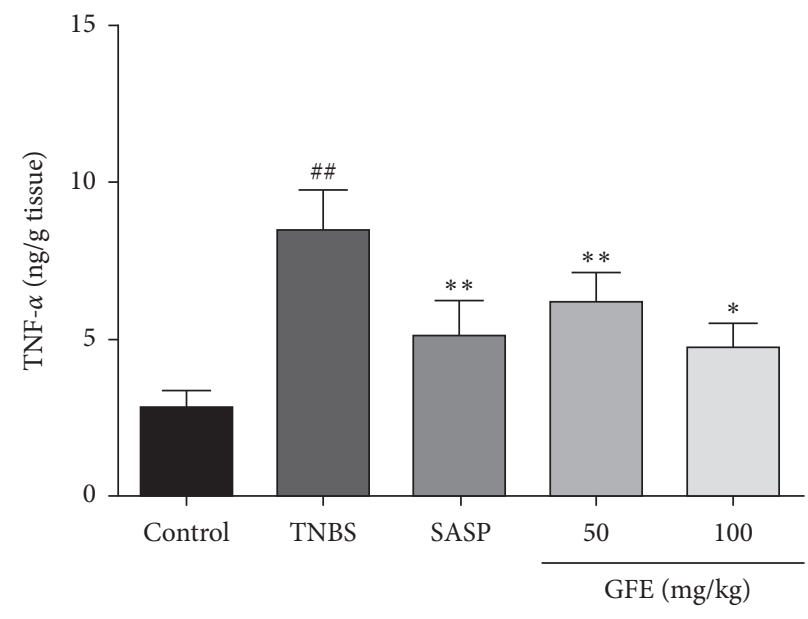

(a)

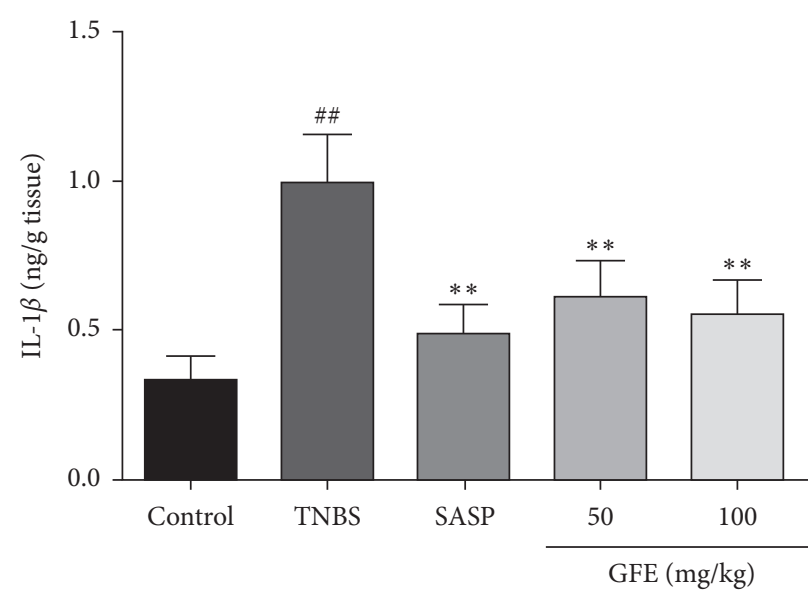

(b)

Figure 6: Continued. 


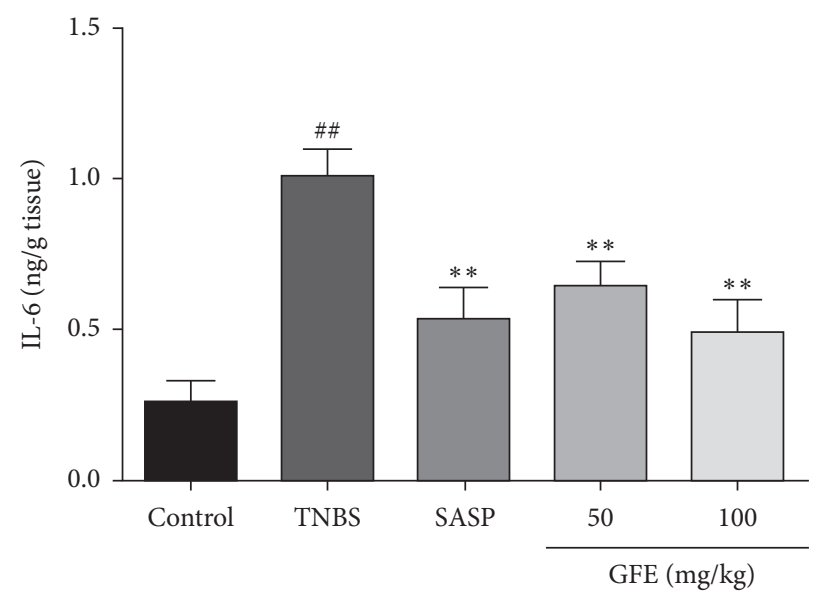

(c)

Figure 6: Effect of different doses of GFE $(50 \mathrm{mg} / \mathrm{kg}, 100 \mathrm{mg} / \mathrm{kg})$ and SASP (500 mg/kg) on TNF- $\alpha$ (a), IL-1 $\beta$ (b), and IL-6 (c). Data are showed as mean $\pm \mathrm{SD}$. ${ }^{\# \#} p<0.001$ vs. control group; ${ }^{*} p<0.05$ and ${ }^{* *} p<0.01$ vs. TNBS group.

compounds from GFE on ulcerative colitis will be investigated in our further research.

\section{Conclusion}

Based on these findings of the current study, treatment with GFE could ameliorate TNBS-induced colitis in rats, and this protective effect of GFE may be mediated through its antiinflammatory and antioxidative properties. GFE could be a potential agent for colitis that deserves further investigation.

\section{Data Availability}

The data used to support the findings of this study are available from the corresponding author upon request.

\section{Conflicts of Interest}

The authors declare that they have no conflicts of interest.

\section{Authors' Contributions}

Jing Liu and Chao Yang contributed equally to this work.

\section{Acknowledgments}

This research work was financially supported by the Program of the National Natural Science Foundation of China (No. 82060710); the Program of Educational Commission of Jiangxi Province (Nos. GJJ201229 and GJJ190678); and the Program of 2018 Training Program for National Bearers of Traditional Chinese Medicinal Techniques (No. T20184828005).

\section{References}

[1] E. Antoniou, G. A. Margonis, A. Angelou et al., "The TNBSinduced colitis animal model: an overview," Annals of Medicine and Surgery, vol. 11, pp. 9-15, 2016.

[2] J. Matricon, N. Barnich, and D. Ardid, "Immunopathogenèse des maladies inflammatoires chroniques de l'intestin," Médecine/Sciences, vol. 26, no. 4, pp. 405-410, 2010.
[3] K. Jessica, J. K. Dyson, and M. D. Rutter, "Colorectal cancer in inflammatory bowel disease: what is the real magnitude of the risk?" World Journal of Gastroenterology, vol. 18, p. 3839, 2012.

[4] I. Ordás, L. Eckmann, M. Talamini, D. C. Baumgart, and W. J. Sandborn, "Ulcerative colitis," The Lancet, vol. 380, pp. 1606-1619, 2012.

[5] C. Stevens, G. Walz, C. Singaram et al., "Tumor necrosis factor, interleukin-1, and interleukin-6 expression in inflammatory bowel disease," Digestive Diseases and Sciences, vol. 37, no. 6, pp. 818-826, 1992.

[6] A. Triantafyllidi, T. Xanthos, A. Papalois, and J. K. Triantafillidis, "Herbal and plant therapy in patients with inflammatory bowel disease," Annals of Gastroenterology, vol. 28, pp. 210-220, 2015.

[7] Y.-H. Hwang, D.-G. Kim, W. Li, H. J. Yang, N.-H. Yim, and J. Y. Ma, "Anti-inflammatory effects of Forsythia suspensa in dextran sulfate sodium-induced colitis," Journal of Ethnopharmacology, vol. 206, pp. 73-77, 2017.

[8] S. Murakami, Y. Tasaka, S. Takatori, A. Tanaka, H. Kawasaki, and H. Araki, "Effect of Eucommia ulmoides Leaf extract on chronic dextran sodium sulfate-induced colitis in mice," Biological and Pharmaceutical Bulletin, vol. 41, no. 6, pp. 864-868, 2018.

[9] J. Zhou, T. Wang, Y. Dou et al., "Brusatol ameliorates 2, 4, 6trinitrobenzenesulfonic acid-induced experimental colitis in rats: involvement of NF- $\kappa$ B pathway and NLRP3 inflammasome," International Immunopharmacology, vol. 64, pp. 264-274, 2018.

[10] Y.-Y. Sung, A. Y. Lee, and H. K. Kim, "The Gardenia jasminoides extract and its constituent, geniposide, elicit antiallergic effects on atopic dermatitis by inhibiting histamine in vitro and in vivo," Journal of Ethnopharmacology, vol. 156, pp. 33-40, 2014.

[11] H. Y. Ni, Z. H. Zhang, and H. Z. Fu, "Research and development of Fructus Gardeniae," China Journal of Chinese Materia Medica, vol. 31, pp. 538-541, 2006.

[12] M. Fukutake, N. Miura, and M. Yamamoto, "Suppressive effect of the herbal medicine Oren-gedoku-to on cyclooxygenase- 2 activity and azoxymethane-induced aberrant crypt foci development in rats," Cancer Letters, vol. 157, no. 1, pp. 9-14, 2000. 
[13] H.-J. Koo, K.-H. Lim, H.-J. Jung, and E.-H. Park, “Anti-inflammatory evaluation of gardenia extract, geniposide and genipin," Journal of Ethnopharmacology, vol. 103, no. 3, pp. 496-500, 2006.

[14] B. Xu, Y.-l. Li, M. Xu et al., "Geniposide ameliorates TNBSinduced experimental colitis in rats via reducing inflammatory cytokine release and restoring impaired intestinal barrier functionflammatory cytokine release and restoring impaired intestinal barrier function," Acta Pharmacologica Sinica, vol. 38, no. 5, pp. 688-698, 2017.

[15] H. Zatorski, M. Sałaga, M. Zielińska et al., "Experimental colitis in mice is attenuated by topical administration of chlorogenic acid," Naunyn-Schmiedeberg's Archives of Pharmacology, vol. 388, no. 6, pp. 643-651, 2015.

[16] Y. Huang, J. Yin, J.-P. Gao, Y. Wang, L. Dong, and J.-H. Zhao, "Portulacaoleraceal extract alleviates trinitrobenzene sulfonic acid-induced colitis in rats," Biomedicine \& Pharmacotherapy, vol. 105, pp. 434-439, 2018.

[17] H. S. Cooper, S. N. Murthy, R. S. Shah, and D. J. Sedergran, "Clinicopathologic study of dextran sulfate sodium experimental murine colitis," Laboratory investigation; a journal of technical methods and pathology, vol. 69, pp. 238-249, 1993.

[18] A. D. Millar, D. S. Rampton, C. L. Chander et al., "Evaluating the antioxidant potential of new treatments for inflammatory bowel disease using a rat model of colitis," Gut, vol. 39, no. 3, pp. 407-415, 1996.

[19] Y.-H. Wang, J. Dong, J.-X. Zhang, J. Zhai, and B. Ge, "Effects of mimic of manganese superoxide dismutase on 2,4,6-trinitrobenzene sulfonic acid-induced colitis in rats," Archives of Pharmacal Research, vol. 39, no. 9, pp. 1296-1306, 2016.

[20] X. Zhang, Z. Pi, Z. Zheng, Z. Liu, and F. Song, "Comprehensive investigation of in-vivo ingredients and action mechanism of iridoid extract from Gardeniae Fructus by liquid chromatography combined with mass spectrometry, microdialysis sampling and network pharmacology," Journal of Chromatography B, vol. 1076, pp. 70-76, 2018.

[21] Y. Han, J. Wen, T. Zhou, and G. Fan, "Chemical fingerprinting of Gardenia jasminoides Ellis by HPLC-DAD-ESIMS combined with chemometrics methods," Food Chemistry, vol. 188, pp. 648-657, 2015.

[22] B. Kalyanaraman, "Teaching the basics of redox biology to medical and graduate students: oxidants, antioxidants and disease mechanisms," Redox Biology, vol. 1, no. 1, pp. 244-257, 2013.

[23] M. Yuksel, I. Ates, M. Kaplan et al., "Is oxidative stress associated with activation and pathogenesis of inflammatory bowel disease?" Journal of Medical Biochemistry, vol. 36, no. 4, pp. 341-348, 2017.

[24] D.-Y. Liu, Y.-M. Guan, H.-M. Zhao et al., "The protective and healing effects of Si Shen Wan in trinitrobenzene sulphonic acid-induced colitis," Journal of Ethnopharmacology, vol. 143, no. 2, pp. 435-440, 2012.

[25] D. Bouzid, B. Gargouri, R. Mansour et al., "Oxidative stress markers in intestinal mucosa of Tunisian inflammatory bowel disease patients," Saudi Journal of Gastroenterology, vol. 19, no. 3, pp. 131-135, 2013.

[26] Y. Jin, J. Yang, L. Lin, Y. Lin, and C. Zheng, “The attenuation of scutellariae radix extract on oxidative stress for colon injury in lipopolysaccharide-induced RAW264.7 cell and 2,4,6-trinitrobenzene sulfonic acid-induced ulcerative colitis rats," Pharmacognosy Magazine, vol. 12, pp. 153-159, 2016.

[27] B. Zingarelli, C. Szabó, and A. L. Salzman, "Reduced oxidative and nitrosative damage in murine experimental colitis in the absence of inducible nitric oxide synthase," Gut, vol. 45, no. 2, pp. 199-209, 1999.
[28] L. Fei and K. Xu, "Zhikang Capsule ameliorates dextran sodium sulfate-induced colitis by inhibition of inflammation, apoptosis, oxidative stress and MyD88-dependent TLR4 signaling pathway," Journal of Ethnopharmacology, vol. 192, pp. 236-247, 2016.

[29] J. P. Eiserich, M. Hristova, C. E. Cross et al., "Formation of nitric oxide-derived inflammatory oxidants by myeloperoxidase in neutrophils," Nature, vol. 391, no. 6665, pp. 393-397, 1998.

[30] K. Amirshahrokhi, S. Bohlooli, and M. M. Chinifroush, "The effect of methylsulfonylmethane on the experimental colitis in the rat," Toxicology and Applied Pharmacology, vol. 253, no. 3, pp. 197-202, 2011.

[31] W. Strober and I. J. Fuss, "Proinflammatory cytokines in the pathogenesis of inflammatory bowel diseases," Gastroenterology, vol. 140, no. 6, pp. 1756-1767, 2011.

[32] L. Cui, L. Feng, Z. H. Zhang, and X. B. Jia, "The anti-inflammation effect of baicalin on experimental colitis through inhibiting TLR4/NF- $\kappa \mathrm{B}$ pathway activation," International Immunopharmacology, vol. 23, no. 1, pp. 294-303, 2014.

[33] W. Fukuda, T. Takagi, K. Katada et al., "Anti-inflammatory effects of carbon monoxide-releasing molecule on trinitrobenzene sulfonic acid-induced colitis in mice," Digestive Diseases and Sciences, vol. 59, no. 6, pp. 1142-1151, 2014.

[34] J. He, J. Liang, S. Zhu, W. Zhao, Y. Zhang, and W. Sun, "Protective effect of taurohyodeoxycholic acid from Pulvis Fellis Suis on trinitrobenzene sulfonic acid induced ulcerative colitis in mice," European Journal of Pharmacology, vol. 670, no. 1, pp. 229-235, 2011.

[35] M. Coccia, O. J. Harrison, C. Schiering et al., "IL- $1 \beta$ mediates chronic intestinal inflammation by promoting the accumulation of IL-17A secreting innate lymphoid cells and CD4+ Th17 cells," Journal of Experimental Medicine, vol. 209, no. 9, pp. 1595-1609, 2012.

[36] P. Zhang, F. L. Niu, W. Z. Liu, Y. Shi, and L. G. Lu, "Antiinflammatory mechanism of oxymatrine in dextran sulfate sodium-induced colitis of rats," World Journal of Gastroenterology, vol. 11, pp. 4912-4915, 2005.

[37] X.-L. Yang, T.-K. Guo, Y.-H. Wang et al., "Ginsenoside Rd attenuates the inflammatory response via modulating p38 and JNK signaling pathways in rats with TNBS-induced relapsing colitis," International Immunopharmacology, vol. 12, no. 2, pp. 408-414, 2012.

[38] F. Yin, J. Liu, X. Zheng, L. Guo, and H. Xiao, "Geniposide induces the expression of heme oxygenase-1 via PI3K/Nrf2Signaling to enhance the antioxidant capacity in primary hippocampal neurons," Biological and Pharmaceutical Bulletin, vol. 33, no. 11, pp. 1841-1846, 2010.

[39] K. N. Nam, Y.-M. Park, H.-J. Jung et al., "Anti-inflammatory effects of crocin and crocetin in rat brain microglial cells," European Journal of Pharmacology, vol. 648, no. 1-3, pp. 110-116, 2010.

[40] Y. Chen, H. Zhang, X. Tian et al., "Antioxidant potential of crocins and ethanol extracts of Gardenia jasminoides ELLIS and Crocus sativus L.: a relationship investigation between antioxidant activity and crocin contents," Food Chemistry, vol. 109, no. 3, pp. 484-492, 2008.

[41] N. Yun, J.-W. Kang, and S.-M. Lee, "Protective effects of chlorogenic acid against ischemia/reperfusion injury in rat liver: molecular evidence of its antioxidant and anti-inflammatory properties," The Journal of Nutritional Biochemistry, vol. 23, no. 10, pp. 1249-1255, 2012.

[42] B. Kroes, A. van den Berg, H. Quarles van Ufford, H. van Dijk, and R. Labadie, "Anti-inflammatory activity of gallic acid," Planta Medica, vol. 58, no. 06, pp. 499-504, 1992. 